University of Texas Rio Grande Valley

ScholarWorks @ UTRGV

\title{
Assessing the mediating role of social support in childhood maltreatment and psychopathology among college students in Northern Ireland
}

\author{
Susan Lagdon \\ Jana Ross \\ Martin Robinson \\ Ateka A. Contractor \\ Ruby Charak \\ The University of Texas Rio Grande Valley, ruby.charak@utrgv.edu
}

See next page for additional authors

Follow this and additional works at: https://scholarworks.utrgv.edu/psy_fac

Part of the Child Psychology Commons

\footnotetext{
Recommended Citation

Lagdon, S., Ross, J., Robinson, M., Contractor, A. A., Charak, R., \& Armour, C. (2021). Assessing the Mediating Role of Social Support in Childhood Maltreatment and Psychopathology Among College Students in Northern Ireland. Journal of Interpersonal Violence, 36(3-4), NP2112-2136NP. https://doi.org/ $10.1177 / 0886260518755489$

This Article is brought to you for free and open access by the College of Liberal Arts at ScholarWorks @ UTRGV. It has been accepted for inclusion in Psychological Science Faculty Publications and Presentations by an authorized administrator of ScholarWorks @ UTRGV. For more information, please contact justin.white@utrgv.edu, william.flores01@utrgv.edu.
} 


\section{Authors}

Susan Lagdon, Jana Ross, Martin Robinson, Ateka A. Contractor, Ruby Charak, and Cherie Armour 


\section{Assessing the mediating role of social support in childhood maltreatment and psychopathology among college students in Northern Ireland}

Susan Lagdon ${ }^{1}$, Jana Ross², Martin Robinson ${ }^{2}$, Ateka A Contractor ${ }^{3}$, Ruby Charak ${ }^{4}$, Cherie Armour $^{5^{*}}$

\section{Author Affiliations:}

${ }^{1}$ School of Nursing \& Midwifery, Queens University Belfast, Northern Ireland, UK

${ }^{2}$ School of Psychology, Ulster University, Coleraine, Northern Ireland, UK

${ }^{3}$ Department of Psychology, University of North Texas, Denton, TX, USA

${ }^{4}$ Department of Psychological Science, The University of Texas Rio Grande Valley, Edinburg, Texas, USA

${ }^{5}$ Faculty of Life and Health Sciences, Ulster University, Coleraine, Northern Ireland, UK

*Address correspondence to:

Cherie Armour, School of Psychology, University of Ulster, Coleraine, Northern Ireland, UK

Email: armour.cherie@gmail.com; Phone: (0044) 02870123374.

The Authors have no conflict of interest to declare.

APA citation: Lagdon, S., Ross, J., Robinson, M., Contractor, A. A., Charak, R., \& Armour, C. (2021). Assessing the Mediating Role of Social Support in Childhood Maltreatment and Psychopathology Among College Students in Northern Ireland. Journal of Interpersonal Violence, 36(3-4), NP2112-2136NP. https://doi.org/10.1177/0886260518755489 


\begin{abstract}
The detrimental impact of early trauma, particularly childhood maltreatment, on mental health is well documented. Although it is understood that social support can act as a protective factor towards mental health for children who experience such adversity, few studies have addressed the experience of childhood maltreatment and the important function of social support in adulthood. The current study aimed to assess the mediating role of social support in the relationship between childhood experiences of maltreatment, and mental health outcomes including anxiety, depression, PTSD and problematic alcohol use in a sample of university students $(N=640)$. Results of binary logistic regression analyses indicated that those reporting experiences of childhood maltreatment were at increased odds of mental health outcomes of PTSD, anxiety and depression, but not alcohol use. Those reporting greater social support were significantly less likely to report on these mental health outcomes. Additionally, the indirect paths from childhood maltreatment through social support to PTSD, depression and anxiety were all significant, suggesting that social support, particularly family support, is a significant mediator of these relationships. Such findings have important implications for the social care response to children experiencing maltreatment and future support for such children as they transition to adolescence and adulthood.
\end{abstract}

Keywords. Childhood Abuse, Maltreatment, Mental Health, Social Support 


\section{Introduction}

Extensive research indicates that a significant proportion of children experience maltreatment, which in turn relates to adverse psychological outcomes. Of note, a great degree of variability in the definition of maltreatment across studies limits consistent meaningful interpretations (Butchart, Harvey, Mian, \& Furniss, 2006). That being said, maltreatment experiences are broadly categorised into four main areas, namely, physical abuse (e.g., hitting, kicking, shaking, or other shows of force against a child), sexual abuse (engaging a child in sexual acts such as fondling, rape, and exposing a child to other sexual activities), psychological or emotional abuse (behaviours that harm a child's self-worth or emotional well-being including name calling, shaming, rejection, withholding love) and neglect (the failure to meet a child's basic needs such as provision of adequate food and clothing as well as protecting the child from harm) (DiLauro, 2004; Davies, 2013). Children are at risk of such harm by not only their parents, but also individuals close to them including siblings, extended family, and family friends (Davies, 2013). Children in many cases may be too young or too afraid to disclose their maltreatment experiences (Bentley, O'Hagan, Raff, \& Bhatti, 2016). Childhood witnessing of domestic violence has also been noted as significantly associated with childhood maltreatment and subsequent detrimental psychological outcomes (Tsavoussis, Stawicki, Stoicea, \& Papadimos, 2014).

Regional estimates of childhood maltreatment tend to be based on official reports to the authorities. Across the whole of the United Kingdom it is estimated that 57,000 children are in need of protection from some form of childhood maltreatment (Bentley, O'Hagan, Raff, \& Bhatti, 2016). Within Northern Ireland there is an estimated 433,161 children residing in the region, of which 24,500 (5.70\%) have been identified by Social Services as 'a child in need.' Children in need are those who require provision of services to negate the impact of their current circumstance on social, educational or health outcomes (Northern Ireland Statistics \& Research Agency, 2016). Childhood maltreatment estimates are further complicated when we consider not only the definition used, but also the type of maltreatment studied (Radford, Corral, Bradley, Fisher, Bassett, Howat, \& Collishaw, 2011). To date, much of the existing literature has tended to focus on one form of maltreatment in relation to risk and associated outcomes of such experiences (Edwards, Holden, Felitti, \& Anda, 2003). Most notably, research on the impact of physical and sexual abuse in childhood has reported that such abuse not only adversely impacts physical health, but also the long term psychopathology of children as they transition into adolescence and adulthood (MacMillan et 
al., 2001, Springer, Sheridan, \& Carnes, 2007, Beach et al., 2013). Within Northern Ireland it is estimated that 250,000 adults and 45,000 children and young people have a mental health need at any one time, equating to one in six of the population (Department of Health, Social Services and Public Safety NI, 2014). The provision of constructive support in order to mitigate the impacts of adverse mental health and the needs of children at risk is particularly important for Northern Ireland. As previously noted, outcomes associated with childhood maltreatment include risk of both physical and psychological harm as well as developmental impacts. The literature suggests that experiencing some forms of childhood maltreatment can result in the development of mental health disorders including posttraumatic stress disorder (PTSD), anxiety, and depression (Arnow, 2004). For example, Wise et al. (2001) implemented a case control study to assess the association between childhood maltreatment in the form of physical and/or sexual abuse. The researchers found that compared with their non-abused counterparts, those who had experienced physical abuse were 2.2 times more likely to also experience depression, those who had experienced sexual abuse were 1.8 times more likely to experience depression, and the risk was 3.3 times higher for those reporting a history of experiencing both types of abuse (Wise et al., 2001).

Further research addressing the relation between childhood physical abuse and PTSD noted that even after controlling for other traumatic experiences such as war and combat exposure, childhood maltreatment is still a significant predictor of adult PTSD development (Yehuda, \& Charney, 1993). The development of PTSD in this manner is suggested to be the result of early experiences of stress which form templates in the brain fixing a fear response for the purpose of survival (Teicher, 2000). The results are that children exposed to maltreatment are constantly in states of high alert that could assist them to avoid further abuse but are costly to their optimal development (Vondra, Barnett, \& Cicchetti, 1990; Connor et al, 2003, Saltzman, 2005). Edwards et al. (2003) utilised a community sample ( $N$ $=8667)$ of both males $(45.8 \%)$ and females $(54.2 \%)$ and found "an overall trend for poorer mental health as the number of abuse types increased was confirmed, implying that a doseresponse relation is present" (p.5). It is also worth noting that Edwards et al. (2003) using the mental health scale of the Medical Outcomes Study 36-item Short-Form Health Survey (Ware \& Sherbourne, 1992), found that although females reported a higher frequency of experiencing multiple forms of abuse compared to males, males reported significantly higher mental health scores than females $(M=78.8, S D=15.5$, versus $M=74.8, S D=16.6)$ indicating poorer mental health among males. Such findings are contrary to the majority of child maltreatment literature, which reports that females fare worse as a result of childhood 
maltreatment and subsequent outcomes (Dhaliwal, Gauzas, Antonowicz \& Ross, 1996, Wegman \& Stetler, 2009).

Drug and alcohol related issues as a result of early trauma are also often cited as being the result of maladaptive coping or self-medication in dealing with early trauma exposure (Widom, \& Hiller-Sturmhofel, 2001). Differences across gender in relation to outcomes associated with childhood maltreatment have also been found in relation to drug and alcohol abuse in adulthood (Widom, \& Hiller-Sturmhofel, 2001). For example, McClellan, Farabee, and Crouch (1997) using a comparative sample of male and female prisoners who had experienced childhood maltreatment, found that adult depression and substance misuse were more prominent among female prisoners. Similarly, in a national survey on adolescence from the US, it was found that among those with experiences of maltreatment, females (vs. males) were more likely to endorse polysubstance use than experimental use of substances (Charak, Koot, Dvorak, Elklit, \& Elhai, 2015).

Although the impact of childhood maltreatment has been shown to be detrimental to the well-being of those exposed to such early trauma, research has also reported that not all children go on to report long-term negative outcomes (Rutter, 2006, Collishaw et al. 2007, Folger, \& Wright, 2013). Researchers such as Cohan and Wills (1985) and Frydenberg (2004) highlighted the importance of protective factors that act to shield an individual from developing problems in the face of adversity. Generally, research addressing trauma exposed populations tends to focus on individual components of interest, that is, those who have experienced childhood maltreatment and subsequent mental health outcomes (Springer, Sheridan, Kuo \& Carnes, 2007). What research studies fail to consider is that these experiences tend to happen within a social system in which an individual is embedded (Southwick et al., 2016). These systems are complex and may differ at the micro level. Some individuals may have stronger support systems at the individual level compared to others, which makes them better able to cope in the face of adversity (Cohan, 2004). Factors such as social support from family and peers (including emotional and instrumental assistance, Pearson, 1983), and healthy relationships with supportive adults, influence a child's healthy development and can help buffer potential adverse psychological consequences (Cohan \& Wills, 1985, Cohan, Underwood, \& Gottlieb. 2000, Frydenberg, 2004, Sperry, \& Widom, 2013).

The advantage of social support towards building resilience is said to be the result of an individual's 'perceived' or 'received' support'. Perceived support refers to subjective feelings towards the support providers and what they can offer (or effective help they have 
offered) during times of need (Haber, Cohen, Lucas, \& Baltes, 2007). This type of support is particularly important in relation to resilience and coping as if an individual believes that significant resource is available during times of stress, they are more likely to believe they can cope with adverse circumstances. 'Received support' on the other hand relates to available supportive actions (e.g., advice or comfort) offered usually during an individual's time of need (Haber, Cohen, Lucas, \& Baltes, 2007). Although received support has been noted as providing beneficial functions, the literature suggests that perceived social support offers greater benefits towards mental health (McDowell \& Serovich, 2007). For example, Seeds', Harkness and Quilty (2010), reported that lower levels of perceived social support was associated with depressive symptoms in a group of adolescents who had experienced childhood maltreatment and/ or peer bulling $(n=101)$. The researchers noted that maltreatment and bullying were "related to depressive symptoms through adolescents" perceptions that they are isolated from their support system and that others will be unavailable to assist them when they need aid” (p.8). Similarly, Väänänen, Marttunen, Helminen, \& Kaltiala-Heino, (2014) using a sample of 2038 adolescents taking part in the Adolescent Mental Health Cohort (AMHC) Study, investigated the relationship between perceived social support and mental health. The researchers found that those reporting lower levels of perceived social support were more likely to report depression.

Although it is well understood that social support can act as a protective factor for children during these early experiences, fewer studies have addressed the experience of childhood maltreatment and social support in adulthood (Sperry \& Widom, 2013); and the extent to which social support is associated with adult psychopathology. Furthermore, in favour of the social support deterioration model perspective, Oshio, Umeda and Kawakami (2012) suggest that in some cases, 'social support moderates or buffers the negative impact of childhood maltreatment but it is also possible that social support mediates, rather than moderates, the impact of such experiences on mental health in adulthood' (p.2). Research by Sperry and Widom (2013) addressed this quandary in their prospective cohort study including adults with a history of childhood maltreatment. The researchers found that those who had experienced childhood maltreatment reported lower levels of perceived social support in adulthood compared to those who had never had this experience. That said, social support was found to mediate the association between childhood maltreatment and anxiety and depression in adulthood but not illegal drug use (Sperry \& Widom, 2013).

Conversely, studies have also documented that adults reporting childhood maltreatment also report lower levels of social support from friends and family (Pepin \& 
Banyard, 2006. Previous research has identified problems in social relationships, for example loss of trust, as a salient issue for survivors of childhood maltreatment (Bourdon \& Cook, 1993), making it difficult for such individuals to form nurturing peer relationships particularly during childhood through to adolescence (Kim \& Cicchetti, 2014; VaillancourtMorel et al., 2016). Additionally, it has been evidenced that childhood maltreatment can impact on children and adolescences behavioural and psychosocial functioning (Diaz, \& Petersen, 2014).). This in turn can result in peer rejection, as noted by Kim and Cicchetti (2010), 'those who have experienced childhood maltreatment report problematic peer relations at disproportionately high rates.' Furthermore, survivors of childhood maltreatment have also been found to have difficulties establishing and maintaining healthy intimate relationships in adulthood (Colman \& Widom, 2004), they have greater fear of intimacy and prefer distance in interpersonal relationships (Reyome, 2010), which could potentially be associated with lower perceived social support from one's intimate partner. Nevertheless, considering the study by Sperry and Widom (2013), it would appear that if social support is available to individuals who have experienced childhood maltreatment; it serves as a protective factor against negative mental health outcomes.

The work of Sperry and Widom (2013) highlighted the important mediating function of social support for adults who have experienced childhood maltreatment. Moving beyond the work of Sperry and Widom (2013), the current study aimed to assess the mediating role of perceived social support from family, peers, and intimate partners in the relationship between childhood experiences of maltreatment, and mental health outcomes, including, anxiety, depression, PTSD and problematic alcohol use. We hypothesised that 1) those reporting any experience of childhood maltreatment will be more likely to also report mental health problems, such as PTSD, depression, anxiety, and alcohol usage; 2) those reporting greater social support will be less likely to report on these mental health problems; and 3) social support will act as a mediator between childhood maltreatment and mental health outcomes, such as PTSD, depression, anxiety and problematic alcohol usage. In other words, social support may lead to decreased negative mental health outcomes among those who experience childhood maltreatment.

\section{Method}

\section{Participants}

The present study was conducted as part of a research programme examining the effects of multiple forms of trauma, including childhood maltreatment and intimate partner 
violence (IPV), on mental health outcomes among students attending a University in Northern Ireland between October 2014 and March 2015. All procedures were approved by the institutional ethics committee. A total of 25,000 participation invitations were distributed via e-mail through the university's mailing system. The email contained details of the survey and a link to complete it via Qualtrics. Participants were provided with an incentive for participation, they were entered into a lottery to win one of six Amazon vouchers redeemable for $£ 50$ each. A total of 1,416 responses were received yielding a response rate of $6 \%$, an unsurprisingly low rate considering that of other studies examining experience of childhood maltreatment (Hovdestad, Campeau, Potte, \& Tonmyr, 2015). Of these, 750 participants were excluded for not completing the relevant measures or for missing over $20 \%$ of data on one or more of the measures. Additionally, we excluded 26 participants who did not report the relevant demographic information, leaving an effective sample of 640 university students.

\section{Measures}

Sociodemographic Characteristics: Relevant sociodemographic characteristics included in the current study were participants' gender, age and relationship status. Gender and relationship status were used as binary variables, with the latter coded as 'in relationship' and 'not in relationship'.

Social Support: The Multidimensional Scale of Perceived Social Support (MSPSS; Zimet, Dahlem, Zimet, \& Farley, 1988) is a 12-item scale measuring individually perceived social support across three domains: support from friends, family and from a significant other i.e. intimate partner (4 items each). Responses are recorded on a 7-point Likert scale ranging from "Very strongly disagree" (1) to "Very strongly agree" (7). Total social support scores are calculated by summing up all responses and dividing this by 12 . Subscale scores are calculated by summing up responses on each subscale and dividing this by 4 . Cronbach's alpha in the current sample was .95 for the whole measure and $.95, .94$ and .97 for friends, family and significant other respectively.

Childhood Maltreatment: Childhood maltreatment was screened using four items adopted from Christoffersen, Armour, Lasgaard, Andersen, and Elklit (2013). These items recorded the frequency with which respondents reported experiencing physical, psychological and sexual abuse as well as exposure to neglect before the age of 12. Responses for these items ranged from 1 (Never) to 6 (Almost Always). This was then used to produce a binary coded variable denoting the presence or absence of exposure to any form of maltreatment. Those who reported "Never" or "Hardly ever" experiencing any form of maltreatment were coded as 'Not maltreated' (coded as 2), and those who reported "Occasionally", 
"Sometimes", "Frequently", or "Almost always" experiencing any of the four forms of maltreatment were coded being in the 'Maltreated' group (coded as 1).

Posttraumatic stress disorder (PTSD): PTSD was assessed using the PTSD Checklist for DSM-5 (PCL-5; Weathers, Litz, Keane, Palmieri, Marx, \& Schnurr, 2013). The PCL-5 is a standardised 20-item self-report inventory measuring the respondents' experience of PTSD symptomatology according to DSM-5 criteria (APA, 2013). Each item questions to what extent, ("Not at all" to "Extremely"), respondents have suffered from specific symptoms of PTSD. Scores on the PCL-5 range from 0 to 80 with higher scores being indicative of greater symptomatology. The present study divided respondents into "Symptomatic" and "Non-symptomatic" groups using the recommended cut off score of 33 (Weathers et al., 2013). The PCL-5 has good psychometric properties in a variety of populations (Wilkins, Lang, \& Norman, 2011), and good internal consistency in the current sample ( $\alpha=.96)$.

Depression: Depression was assessed using the Patient Health Questionnaire-9 (PHQ-9; Kroenke, Spitzer, \& Williams, 2001). The PHQ-9 is a widely used screening measure of depressive symptomatology with each item based on the DSM-IV definition of major depressive episode. Questions are posed as to what extent respondents have experienced depressive symptoms over the previous two weeks ranging from "Not at all" to "Nearly every day" with a possible score range of 0 - 27. A cut-off score of 10 was chosen for the current study as this has been shown previously to be reliable in distinguishing symptomatic and non-symptomatic groups (Kroenke et al., 2001, Tamburrino, Elhai, Prescott, Cohen, et al., 2013). The internal consistency of PHQ-9 was good in the current sample $(\alpha=.92)$.

Anxiety: Anxiety was assessed using the Generalized Anxiety Disorder Assessment (GAD-7; Spitzer, Kroenke, Williams, \& Lowe, 2006). The GAD-7 is a 7-item questionnaire screening for the frequency of experienced symptoms of anxiety over the previous two weeks. Scores range from 0 ("Not at all") to 3 ("Nearly every day") yielding a total possible score range of $0-21$. The GAD-7 is a reliable screening tool of anxiety disorders in the general population (Löwe et al., 2008) and in the current sample, it had good internal consistency $(\alpha=.918)$. According to the recommendations of Spitzer et al. (2006) the current study used a cut-off score of 10 to distinguish symptomatic and non-symptomatic groups.

Problematic Alcohol Use was assessed using the Alcohol Use Disorders Identification Test (AUDIT; Babor, Higgins-Biddle, Saunders, \& Monteiro, 2001). The AUDIT is a 10-item screening tool for the presence of harmful and hazardous alcohol use as well as alcohol dependence. Responses are coded ranging from $0-4$ for each item, yielding a 
possible score range of 0 - 40 for the entire measure. Balodis, Potenza, \& Olmstead (2009) noted that frequent alcohol consumption and binge drinking behaviours may be considered common in the U.K. student population and hence the current study utilised a cut off score of 10 to distinguish the problematic and non-problematic alcohol consumption groups. The AUDIT has good psychometric properties as a self-report measure of alcohol use and the recommended cut off score of 10 has been validated in groups where alcohol consumption is normal (Daeppen, Yersin, Landry, Pécoud, \& Decrey, 2000; Babor et al., 2001). The internal reliability in the current study was good $(\alpha=.82)$.

\section{Data analysis}

The total amount of missing data in the effective sample $(N=640)$ was $0.29 \%$ and Little's MCAR test showed that the data was missing completely at random $\chi^{2}=3167.060, d f$ $=3280, p=.920$. The expectation maximization algorithm was used to impute the missing values.

The analysis was conducted in three steps involving binary logistic regressions. First, in Model 1, the binary coded childhood maltreatment was specified as a predictor of the binary coded mental health outcomes (PTSD, depression, anxiety, alcohol use). The covariates (gender, age, relationship status) and the three mediator variables (social support from friends, from family, and from a significant other i.e., intimate partner) were included in the model, but their pathways were fixed to zero. The reason for this was to keep the number of parameters equal across the models to enable their direct comparison. In Model 2, the paths from the covariates to the mental health outcomes were freed and estimated alongside the paths from childhood maltreatment to the mental health outcomes. Gender and relationship status were entered into the model as binary variables and age was used as a continuous variable. The paths to and from the mediator variables remained fixed. Finally, in Model 3 social support from family, friends and a significant other served as mediators between childhood maltreatment and the demographic covariates on one side and the mental health outcomes on the other side. The paths to and from social support were therefore freely estimated in Model 3. Figure 1 depicts the final mediation model. All models were estimated in Mplus 7.3 (Muthén \& Muthén, 2015) using the robust maximum likelihood estimator (MLR).

\section{***FIGURE ONE HERE***}

\section{Results}

In the effective sample of 640 participants, 167 (26.09\%) experienced one or more forms of childhood maltreatment. Of these, 92 (14.38\%) experienced only one type of 
maltreament, 55 (8.59\%) experienced two types, 13 (2.03\%) experienced three types and seven participants (1.09\%) experienced all four types of childhood maltreatment. Overall, psychological maltreatment was the most common, reported by $19.22 \%(n=123)$ of the

whole sample, followed by physical maltreatment $(16.88 \%, n=108)$, neglect $(3.75 \%, n=24)$ and sexual maltreatment $(2.19 \%, n=14)$. Table 1 presents the demographic information and the descriptive statistics for the social support variables and the different measures of mental health outcomes by childhood maltreatment.

\section{***TABLE ONE HERE***}

The three social support variables showed moderate to strong correlations with each other $\left(r_{s}=.49\right.$ to $\left..61, p<.01\right)$, suggesting that social support from friends, family and significant other are distinct constructs. Multicollinearity between the social support variables was not a problem in the current sample $($ Tolerance $=.51$ to $.58 ; \mathrm{VIF}=1.73$ to 1.96$)$. Since the relationship status and social support from a significant other are also conceptually related, we examined the relationship between these two constructs using point-biserial correlation. The two constructs were found to be only moderately related $(r=-.37, p<.01)$, suggesting that individuals in a relationship are more likely to report higher levels of social support from a significant other. Since the correlation was only moderate, both variables were used in subsequent analyses.

The results of the logistic regressions are presented in Table 2. In Model 1, the direct effects from childhood maltreatment to PTSD, depression and anxiety were all significant, with odds ratios ranging from 2.39 to 4.09 . Interestingly, childhood maltreatment did not predict alcohol use. In Model 2, which included the covariates, the direct effects from childhood maltreatment to PTSD, depression and anxiety remained significant (ORs 2.564.03). Some of the covariates also predicted the mental health outcomes; PTSD, depression and anxiety were all predicted by gender with females scoring higher than males on these outcomes. Alcohol use was predicted by male gender. Anxiety was additionally predicted by younger age and those individuals who were not in a relationship were more likely to have alcohol use problems (see Table 2 for ORs and CIs). The chi-square difference test showed that Model 2 fit significantly better than Model $1\left(\chi^{2}=45.644, d f=12, p<.001\right)$. All the paths from childhood maltreatment and the covariates to the mental health outcomes that were significant in Model 2 remained significant in Model 3, which was the full mediation model. By adding the three variables of social support into the model, all the ORs from childhood maltreatment to the mental health outcomes were reduced. Individuals reporting greater social support from family were significantly less likely to score above the cut-off 
point on PTSD, depression and anxiety, suggesting that social support from family acts as a protective factor, reducing the likelihood of these mental health outcomes (see Table 2 for ORs and CIs). Additionally, social support from friends was a significant predictor of anxiety, such that individuals reporting greater support from friends were significantly less likely to score above the cut-off point for anxiety. The indirect paths from childhood maltreatment through social support from family to PTSD, depression and anxiety were all significant and so was the indirect path from childhood maltreatment through social support from friends to anxiety. These types of social support are therefore significant mediators of these relationships. The chi-square difference test showed that Model 3 fit significantly better than Model $2\left(\chi^{2}=277.046, d f=24, p<.001\right)$.

\section{$* * *$ TABLE TWO HERE***}

\section{Discussion}

The current paper assessed the relation between childhood maltreatment, social support and mental health outcomes, including, anxiety, depression, PTSD and problematic alcohol use using a sample of adult university students from Northern Ireland. Firstly, it is important to note that the majority of participants in the current study sample, who reported ever experiencing childhood maltreatment, reported experiencing more than one form of abuse. This finding is consistent with the existing literature which reports that childhood maltreatment is generally not an isolated or singular experience (Charak \& Koot, 2015; Finkelhor et al., 2011; Edwards et al., 2003). Research addressing exposure to multiple forms of childhood maltreatment notes this as a 'complex trauma' whereby children exposed to one form of maltreatment are also likely to be exposed to other forms of abuse and adversity (Charak \& Koot, 2015; Dong et al., 2004; Higgins \& McCabe, 2000). This cumulative risk is said to be the result of exposure to multiple risk factors (Tseloni \& Pease, 2003). It is suggested that a number of risk indicators including, age, gender, socio economic status and home environment including exposure to parental partner violence can increase the possibility of a child experiencing one or more forms of abuse (Tseloni \& Pease, 2003, Finkelhor, Turner, Hamby \& Ormrod, 2011). For example, findings of the US National Survey of Children's Exposure to Violence (NatSCEV) showed that of the 4,549 children aged 17 and under, 38.7\% reported experiencing more than one type of direct victimization in the previous year (Finkelhor et al., 2011). Moreover, the researchers also found that children experiencing more than one form of maltreatment were more likely to reside in families experiencing considerable violence, parental substances misuse and mental health problems and families experiencing financial hardship compared with children experiencing only one 
form of maltreatment (Finkelhor et al. 2011). The current study finding that psychological maltreatment was the most commonly reported form of abuse is not surprising given the known risk factors of childhood maltreatment (Finkelhor et al., 2011). If children reside in homes whereby their parents or care providers' circumstances result in risk of child maltreatment it can be presumed children's emotional needs would be impinged upon. It is suggested that emotional and psychological harm are also core issues in all forms of childhood maltreatment with the greatest potential for harm over time given that effects, unlike physical abuse, are not immediate (Garbarino \& Garbarino, 1994).

A further consistent finding of the current study was the predictive relation between childhood maltreatment and mental health outcomes of PTSD, depression and anxiety (McLafferty, Armour, McKenna, O'Neill, Murphy, \& Bunting, 2015) but not alcohol use (Armour, Shorter, Elhai, Elklit, \& Christofferson, 2014). The number of male participants exposed to childhood maltreatment within the current study was notably smaller than the number of females, which may have contributed to the non-significant relationship between childhood maltreatment and alcohol use. Nevertheless, the finding that females were higher on mental health outcomes of anxiety, depression and PTSD, whereas only males were higher on problematic alcohol use is of interest. As previously noted, a small body of research which has addressed gender disparities in the relation between early trauma and adult psychopathology noted that, although both males and females may be exposed to similar types of maltreatment, subsequent associated outcomes may differ (Trickett, \& McBrideChang, 1995, Thompson, Kingree and Desai, 2004, Charak, Koot, Dvorak et al., 2015). These differences are suggested to be the result of dissimilar coping styles whereby females tend to internalise feelings, thoughts and emotions when distressed whereas males tend to externalise or act out through anti-social behaviours such as problematic alcohol use (Hamblin, 2016). Additionally, some literature suggests that excessive drinking among males who have experienced childhood maltreatment is motivated by attempts to self-regulate emotions associated with anxiety and depression (Goldstein, Flett \& Wekerle, 2010). In this sense, males tend to use alcohol to improve their mood, modulating positive affect rather than coping negative effects (Goldstein, Flett \& Wekerle, 2010). Further understanding of alcohol use motivation in relation to adults, both male and female, who have experienced childhood maltreatment, would be useful. Moreover, the current research findings also highlighted that individuals who were not in a relationship were also more likely to have alcohol use problems thus furthering the notion that social support in adulthood may act as a buffer 
towards such issues. A sample with a greater proportion of males for future exploration would be useful.

Consistent with the work of Sperry and Widom (2013) and the wider social support literature (Cohen, Gottlieb, \& Underwood, 2000) was the finding that those who had experienced childhood maltreatment and reported greater social support were significantly less likely to report PTSD, depression and anxiety, suggesting that social support is an important protective factor in relation to mental health outcomes. More specifically, the current study findings highlight that those reporting greater support from family are less likely to experience PTSD, depression, and anxiety. Additionally, the current study also found that indirect paths from childhood maltreatment through family support to PTSD, depression and anxiety were all significant as was the indirect path from childhood maltreatment through social support from friends to anxiety, suggesting that these types of social support are significant mediators of these relationships.

As previously discussed, the theoretical literature proposes that social support should be viewed as dimensional (Perceived or Received support) (Armstrong, Birnie-Lefcovitch, \& Ungar, 2005), providing a number of functions depending on the transaction between the recipient and the provider. The type of stressor, characteristics and attributes of the recipient and types and sources of available social support influence how social support will function (Taylor, 2011). These functions can be split into emotional, informational, tangible and companionship or sense of belonging (Armstrong, Birnie-Lefcovitch, \& Ungar, 2005). It can be conceived that given the potential for long term bonds with family, an individual may feel and are being provided with most if not all of the functions of social support via family whereas interpersonal relationships with peers or others may only provide some of these functions but not all depending on the state and circumstance of the relationship. If an individual is struggling with previous childhood experiences which are known to elicit feelings of fear, mistrust and isolation (Kendall-Tackett, 2001); the perceived availability of support which also offers feelings of being understood, in control and accompanied, would enhance one's ability to cope effectively. Family in this sense acts as a stress mediator, fostering resilience particularly where adult psychopathology is concerned (Gurung, 2006, Southwick et al. 2016).

\section{Limitations}

The current study was cross-sectional in design unlike the work of Sperry and Widom (2013) which was a cohort design making direct comparisons of findings across both studies difficult. The current study used retrospective reports of childhood maltreatment and did not 
account for poly-victimisation within the mediation model, due to small numbers of participants endorsing different types of maltreatment. Furthermore, the current study did not take into account childhood history of any therapeutic intervention and did not control for type of perpetrators (i.e. family members). Participant's social support was measured via a self-report measure which reflects the participants' perceptions of their current social network provision and not necessarily the support they have been offered/ provided previously. Furthermore, support can also be provided more formally via statutory or voluntary services, which participants may have availed of but was not controlled for; for example current university support services or health and social care support services. That being said the study queries current mental health status (past few weeks) highlighting current support conditions and needs. Finally, the current study did not ask about experiences of trauma beyond 12 years of age thus subsequent trauma was not controlled for in relation to mental health. Nevertheless, the significant mediation findings of social support remain.

\section{Conclusions and Implications}

The current study findings have added to the extant literature reporting on the important implications of childhood maltreatment and subsequent adult psychopathology (Arnow, 2004, Thompson, Kingree \& Desai, 2004, Sperry \& Widom, 2013, McLafferty et al., 2015). Furthermore, study findings further emphasize the important role that social support can play in protecting against such adverse outcomes (Sperry \& Widom, 2013). Within Northern Ireland this is particularly important given the region's high rates of children considered at risk and also the high rates of suicide among young people in this region (Largey, Kelly, \& Stevenson, 2009). Although a direct link has not yet been established, it is suggested that childhood maltreatment may be among some of the adversities associated with suicidal ideation among young people (Devaney, Bunting, Davidson, Hayes, Lazenbatt, \& Spratt, 2012). It is important moving forward that early intervention in response to childhood maltreatment considers the needs of the child and the social system in which a child resides. This could perhaps be best reflected with further development of child protection policies. For example, Thompson (1995) suggested that policy agenda's which encourage a whole family approach to social support to abuse-prone families can potentially prevent child abuse and neglect and protect against subsequent adverse outcomes. Furthermore, if services draw on existing social strengths in the form of family or peer support, children may begin to foster the resilience needed to better protect their mental health as they develop. In this sense, greater consideration is needed by social services for the care pathway in which children may be directed towards in cases of maltreatment whereby the child(ren) may be removed from 
their family home and placed in alternative care. This is particularly salient in relation to 'looked after children'. Furthermore, continued and consistent support (including psycho educational interventions) from services should extend to care-takers of maltreated children and to maltreated children themselves as they transition into adolescence and adulthood.

The current study findings also highlight that a number of young adults attending university have had a childhood maltreatment experience and that this experience has impinged upon their mental health. The University UK's Guidelines on Student Mental Health Policies and Procedures for Higher Education (2015) supports the holistic 'healthy settings' approach to promoting health and wellbeing among students. Whilst many universities offer an array of peer support and information for students regarding mental health, this is type of support facilitates problem focused coping. Moving forward, it is important for both educators and policy makers within higher education to think about and develop strategies to address the needs of those who have experienced childhood maltreatment and consider how perceived social support can be improved among this cohort and incorporated into student well-being and support strategies. Based on current study findings, increased perceived social support should help towards building significant resilience, lessening the adverse mental health symptoms associated with early adversity and allow individuals to better focus on academic success. 


\section{References}

Armour, C., Shorter, G. W., Elhai, J. D., Elklit, A., \& Christofferson, M. N. (2014). Polydrug use typologies and childhood maltreatment in a nationally representative survey of Danish young adults. Journal of Studies on Alcohol and Drugs, 75, 170-178

Armstrong, M. I., Birnie-Lefcovitch, S., \& Ungar, M. T. (2005). Pathways between social support, family well-being, quality of parenting, and child resilience: What we know. Journal of child and family studies, 14(2), 269-281.

Arnow, B. A. (2004). Relationships between childhood maltreatment, adult health and psychiatric outcomes, and medical utilization. Journal of Clinical Psychiatry, 65, 1015.

Babor, T. F., Higgins-Biddle, J. C., Saunders, J. B., \& Monteiro, M. G. (2001). The alcohol use disorders identification test. Guidelines for use in Primary Care. Geneva, Switzerland: World Health Organization.

Beach, S. R., Brody, G. H., Lei, M. K., Gibbons, F. X., Gerrard, M., Simons, R. L., ... \& Philibert, R. A. (2013). Impact of child sex abuse on adult psychopathology: a genetically and epigenetically informed investigation. Journal of Family Psychology, $27(1), 3$.

Bentley, H., O’Hagan, O.,Raff, A., \& Bhatti, I., (2016). How safe are our children? The most comprehensive overview of child protection in the UK 2016. NSPCC

Butchart, A., Harvey, A. P., Mian, M., \& Furniss, T. (2006). Preventing child maltreatment: a guide to taking action and generating evidence. World Health Organisation

Caleb, R. (2015). Students Mental Wellbeing in Higher Education-Good Practice Guide. London: Universities UK.

Charak, R., \& Koot, H. M. (2015). Severity of maltreatment and personality pathology in adolescents of Jammu, India: A latent class approach. Child Abuse and Neglect, 50, 56-66.

Charak, R., Koot, H. M., Dvorak, R. D., Elklit, A., \& Elhai, J. D. (2015). Unique versus cumulative effects of physical and sexual assault on patterns of adolescent substance use. Psychiatry Research, 230, 763-769.

Christoffersen, M. N., Armour, C., Lasgaard, M., Andersen, T. E., \& Elklit, A. (2013). The prevalence of four types of childhood maltreatment in Denmark. Clinical Practice \& Epidemiology in Mental Health, 9(1).

Cohen, S. \& Hoberman, H.M., (1983). Positive events and social supports as buffers of life change stress. Journal of Applied Social Psychology, 13 (2) (1983), pp. 99-125 
Cohen, S. (2004). Social relationships and health. American psychologist, 59(8), 676.

Cohen, S., Gottlieb, B. H., \& Underwood, L. G. (2000). Social relationships and health. In S. Cohen, L. G. Underwood, \& B. H. Gottlieb (Eds.), Social support measurement and intervention: A guide for health and social scientists (pp. 3-25). New York: Oxford University Press.

Cohen, T.A. Wills, (1985) Stress, social support, and the buffering hypothesis. Psychological Bulletin, 98 (2) pp. 310-357

Collishaw, S., Pickles, A., Messer, J., Rutter, M., Shearer, C., \& Maughan, B. (2007).

Resilience to adult psychopathology following childhood maltreatment: Evidence from a community sample. Child abuse \& neglect, 31(3), 211-229.

Colman, R. A., \& Widom, C. S. (2004). Childhood abuse and neglect and adult intimate relationships: a prospective study. Child Abuse \& Neglect, 28(11), 1133-1151. doi: 10.1016/j.chiabu.2004.02.005

Connor, D.F., Doerfler, L.A., Volungis, A.M., Steingard, R.J., Mellomi, R.H., (2003). Aggressive Behavior in Abused Children. Annals of the New York Academy of Sciences. Vol 1008: 79-90.

Daeppen, J., Yersin, B., Landry, U., Pécoud, A., \& Decrey, H. (2000). Reliability and validity of the alcohol use disorders identification test (AUDIT) imbedded within a general health risk screening questionnaire: Results of a survey in 332 primary care patients. Alcoholism: Clinical and Experimental Research, 24(5), 659-665.

Davies, M., (2013. The Blackwell Companion to Social Work. Wiley-Blackwell Department of Health, Social Services and Public Safety NI, (2014). DELIVERING THE BAMFORD VISION. The Response of the Northern Ireland Executive to the Bamford Review of Mental Health and Learning Disability. Accessed February 2017, From https://www.health-ni.gov.uk/sites/default/files/publications/dhssps/deliveringbamford-vision-action-plan.pdf

Devaney, J., Bunting, L., Davidson, G., Hayes, D., Lazenbatt, A. and Spratt, T., (2012) Still Vulnerable The Impact of Early Childhood Experiences on Adolescent Suicide and Accidental Death. Northern Ireland Commissioner for Children and Young People (NICCY)

Dhaliwal, G. K., Gauzas, L., Antonowicz, D. H., \& Ross, R. R. (1996). Adult male survivors of childhood sexual abuse: Prevalence, sexual abuse characteristics, and long-term effects. Clinical Psychology Review, 16(7), 619-639. 
Diaz, A., \& Petersen, A. C. (2014). Institute of Medicine report: new directions in child abuse and neglect research. JAMA pediatrics, 168(2), 101-102.

DiLauro, M. D. (2004). Psychosocial factors associated with types of child maltreatment. Child welfare, 83(1), 69.

Dong, M., Anda, R. F., Felitti, V. J., Dube, S. R., Williamson, D. F., Thompson, T. J., ... \& Giles, W. H. (2004). The interrelatedness of multiple forms of childhood abuse, neglect, and household dysfunction. Child abuse \& neglect, 28(7), 771-784.

Edwards, V. J., Holden, G. W., Felitti, V. J., \& Anda, R. F. (2003). Relationship between multiple forms of childhood maltreatment and adult mental health in community respondents: results from the adverse childhood experiences study. American Journal of Psychiatry, 160(8), 1453-1460.

Fearon, R. P., Bakermans-Kranenburg, M. J., Van IJzendoorn, M. H., Lapsley, A. M., \& Roisman, G. I. (2010). The significance of insecure attachment and disorganization in the development of children's externalizing behavior: a meta-analytic study. Child development, 81(2), 435-456. doi: 10.1111/j.1467-8624.2009.01405.x.

Finkelhor, D., Turner, H., Hamby, S. L., \& Ormrod, R. (2011). Polyvictimization: Children's Exposure to Multiple Types of Violence, Crime, and Abuse. National Survey of Children's Exposure to Violence.

Folger, S. F., \& Wright, M. O. D. (2013). Altering risk following child maltreatment: Family and friend support as protective factors. Journal of Family Violence, 28(4), 325-337.

Frydenberg, E. (2004). Coping competencies: What to teach and when. Theory into practice, 43(1), 14-22.

Garbarino, J. and Garbarino, A.C. (1994), Emotional Maltreatment of Children (rev. edn), National Committee to Prevent Child Abuse, Chicago.

Goldstein, A. L., Flett, G. L., \& Wekerle, C. (2010). Child maltreatment, alcohol use and drinking consequences among male and female college students: An examination of drinking motives as mediators. Addictive behaviors, 35(6), 636-639.

Gurung, R.A.R. (2006). "Coping and Social Support". Health Psychology: A Cultural Approach. Belmont, CA: Thomson Wadsworth. pp. 131-171

Haber, M. G., Cohen, J. L., Lucas, T., \& Baltes, B. B. (2007). The relationship between selfreported received and perceived social support: A meta-analytic review. American journal of community psychology, 39(1-2), 133-144. 
Hamblin, E. (2016). Gender and children and young people's emotional and mental health: manifestations and responses. A rapid review of the evidence. National Children's Bureau

Hovdestad, W., Campeau, A., Potter, D., \& Tonmyr, L. (2015). A systematic review of childhood maltreatment assessments in population-representative surveys since 1990. PloS one, 10(5), e0123366.

Kendall-Tackett, K., (2001). The Long Shadow: Adult Survivors of Childhood Abuse. Chapter from: The hidden feelings of motherhood: Coping with mothering stress, depression and burnout. Oakland, CA: New Harbinger

Kim, J., \& Cicchetti, D. (2010). Longitudinal pathways linking child maltreatment, emotion regulation, peer relations, and psychopathology. Journal of Child Psychology and Psychiatry, 51(6), 706-716. doi: 10.1111/j.1469-7610.2009.02202.x.

Kroenke, K., Spitzer, R.L., Williams, J.B. (2001). The PHQ-9: validity of a brief depression severity measure. Journal of General Internal Medicine, 16, 606-613

Largey, M., Kelly, C. B., \& Stevenson, M. (2009). A study of suicide rates in Northern Ireland 1984-2002. Ulster Med J, 78(1), 16-20.

MacMillan, H. L., Fleming, J. E., Streiner, D. L., Lin, E., Boyle, M. H., Jamieson, E., ... \& Beardslee, W. R. (2001). Childhood abuse and lifetime psychopathology in a community sample. American Journal of Psychiatry, 158(11), 1878-1883.

McClellan, D. S., Farabee, D., \& Crouch, B. M. (1997). Early victimization, drug use, and criminality a comparison of male and female prisoners. Criminal justice and behavior, 24(4), 455-476.

McDowell, T. L., \& Serovich, J. M. (2007). The effect of perceived and actual social support on the mental health of HIV-positive persons. AIDS care, 19(10), 1223-1229.

McLafferty, M., Armour, C., McKenna, A., O'Neill, S., Murphy, S. \& Bunting, B. (2015). Childhood adversity profiles and adult psychopathology in a representative Northern Ireland study. Journal of Anxiety Disorders, 35, 42-48

Muthén, L. K., \& Muthén, B. O. (1998 - 2015). Mplus 7.3 (Seventh ed.). Los Angeles, CA: Muthén \& Muthén.

Northern Ireland Statistics \& Research Agency, 2016 - October 2016 - Children's Social Care Statistics for Northern Ireland 2015/16

Oshio, T., Umeda, M., \& Kawakami, N. (2013). Childhood adversity and adulthood subjective well-being: evidence from Japan. Journal of Happiness Studies, 14(3), 843-860. 
Pearson, J. E. (1986). The definition and measurement of social support. Journal of Counseling \& Development.

Pepin, E. N., \& Banyard, V. L. (2006). Social support: A mediator between child maltreatment and developmental outcomes. Journal of Youth and Adolescence, 35(4), 617-630. doi: 10.1007/s10964-006-9063-4

Radford, L., Corral, S., Bradley, C., Fisher, H., Bassett, C., Howat, N., \& Collishaw, S. (2011). Child abuse and neglect in the UK today.

Reyome, N. D. (2010). Childhood emotional maltreatment and later intimate relationships: Themes from the empirical literature. Journal of Aggression, Maltreatment \& Trauma, 19(2), 224-242. doi: 10.1080/10926770903539664

Rutter, M. (2006). Implications of resilience concepts for scientific understanding. Annals of the New York Academy of Sciences, 1094(1), 1-12.

Saltzman, K.M., Weems, C.F, \& Carrion, V.G., (2005). IQ and Posttraumatic Stress Symptoms in Children Exposed to Interpersonal Violence. Journal of child psychiatry and human development. 36(3), 261-272.

Seeds, P. M., Harkness, K. L., \& Quilty, L. C. (2010). Parental maltreatment, bullying, and adolescent depression: Evidence for the mediating role of perceived social support. Journal of Clinical Child \& Adolescent Psychology, 39(5), 681-692.

Southwick, S. M., Sippel, L., Krystal, J., Charney, D., Mayes, L., \& Pietrzak, R. (2016). Why are some individuals more resilient than others: the role of social support. World Psychiatry, 15(1), 77-79.

Sperry, D. M., \& Widom, C. S. (2013). Child abuse and neglect, social support, and psychopathology in adulthood: A prospective investigation. Child abuse \& neglect, $37(6), 415-425$.

Spitzer, R. L., Kroenke, K., Williams, J. B., \& Lowe, B. (2006). A brief measure for assessing generalized anxiety disorder: The GAD-7. Archives of Internal Medicine, $166,1092-1097$.

Springer, K. W., Sheridan, J., Kuo, D., \& Carnes, M. (2007). Long-term physical and mental health consequences of childhood physical abuse: Results from a large populationbased sample of men and women. Child abuse \& neglect, 31(5), 517-530.

Tamburrino, M., Elhai, J. D., Prescott, M. R., Cohen, G. H., et al. (2013). Validation of the telephone-administered PHQ-9 against the in-person administered SCID-I. Journal of Affective Disorders, 150, 1001-1007. doi: 10.1016/j.jad.2013.05.029 
Taylor, S.E. (2011). "Social support: A Review". In M.S. Friedman. The Handbook of Health Psychology. New York,NY: Oxford University Press.

Thompson, R. A. (1995). Preventing child maltreatment through social support: A critical analysis. Sage Publications, Inc.

Thompson, M. P., Kingree, J. B., \& Desai, S. (2004). Gender differences in long-term health consequences of physical abuse of children: data from a nationally representative survey. American Journal of Public Health, 94(4), 599-604.

Trickett, P. K., \& McBride-Chang, C. (1995). The developmental impact of different forms of child abuse and neglect. Developmental Review, 15, 311-337.

Tsavoussis, A., Stawicki, S. P., Stoicea, N., \& Papadimos, T. J. (2014). Child-witnessed domestic violence and its adverse effects on brain development: a call for societal self-examination and awareness. Frontiers in public health, 2.

Tseloni, A. and Pease, K. (2003). 'Repeat Personal Victimization.'Boosts' or 'Flags'?' British Journal of Criminology 43: 196-212.

Väänänen, J. M., Marttunen, M., Helminen, M., \& Kaltiala-Heino, R. (2014). Low perceived social support predicts later depression but not social phobia in middle adolescence. Health Psychology and Behavioral Medicine: an Open Access Journal, 2(1), 10231037.

Vaillancourt-Morel, M., Godbout, N., Sabourin, S., Briere, J., Lussier, Y., \& Runtz, M. (2016). Adult Sexual Outcomes of Child Sexual Abuse Vary According to Relationship Status. Journal of Marital and Family Therapy, 42(2), 341-356. doi: 10.1111/jmft.12154.

Vondra, J. I., Barnett, D., \& Cicchetti, D. (1990). Self-concept, motivation, and competence among preschoolers from maltreating and comparison families. Child Abuse \& Neglect, 14(4), 525-540.

Ware JE Jr, Sherbourne CD: The MOS 36-Item Short-Form Health Survey (SF-36), I: conceptual framework and item selection. Med Care 1992; 30:473-483

Weathers, F.W., Litz, B.T., Keane, T.M., Palmieri, P.A., Marx, B.P., \& Schnurr, P.P. (2013). The PTSD Checklist for DSM-5 (PCL-5). Scale available fromthe National Center for PTSD at www.ptsd.va.gov.

Wegman, H. L., \& Stetler, C. (2009). A meta-analytic review of the effects of childhood abuse on medical outcomes in adulthood. Psychosomatic medicine, 71(8), 805-812.

Widom, C. S., \& Hiller-Sturmhofel, S. (2001). Alcohol abuse as a risk factor for and consequence of child abuse. Alcohol Research \& Health, 25(1), 52-52. 
Wise, L. A., Zierler, S., Krieger, N., \& Harlow, B. L. (2001). Adult onset of major depressive disorder in relation to early life violent victimisation: a case-control study. The Lancet, 358(9285), 881-887

Yehuda, R., \& Charney, D. S. (1993). Childhood physical abuse and combat-related posttraumatic stress disorder in Vietnam veterans. American Journal of Psychiatry, $150,235-239$.

Zimet, G. D., Dahlem, N. W., Zimet, S. G., \& Farley, G. K. (1988). The multidimensional scale of perceived social support. Journal of personality assessment, 52(1), 30-41. 
Table 1

Demographics and descriptive statistics by childhood maltreatment

\begin{tabular}{|c|c|c|c|}
\hline Variable & $\begin{array}{l}\text { Maltreated group } \\
(n=167)\end{array}$ & $\begin{array}{l}\text { Non-maltreated } \\
\text { group } \\
(n=473)\end{array}$ & \\
\hline Age $M d n$ & 22.00 & 21.00 & $U=33800.50^{* *}$ \\
\hline Gender & & & \\
\hline $\begin{array}{l}\text { Male } N(\%) \\
\text { Female } N(\%)\end{array}$ & $\begin{array}{l}37(22.16) \\
130(77.84)\end{array}$ & $\begin{array}{l}119(25.16) \\
354(74.84)\end{array}$ & $\chi^{2}(1)=.60$ \\
\hline \multicolumn{4}{|l|}{ Relationship status } \\
\hline $\begin{array}{l}\text { In relationship } N(\%) \\
\text { Not in relationship } N(\%)\end{array}$ & $\begin{array}{l}106(63.47) \\
61(36.53)\end{array}$ & $\begin{array}{l}326(68.92) \\
147(31.08)\end{array}$ & $\chi^{2}(1)=1.67$ \\
\hline \multicolumn{4}{|l|}{ PTSD } \\
\hline $\begin{array}{l}\text { Total score } M d n \\
\text { Above/Below cut-off } N(\%)\end{array}$ & $\begin{array}{l}20.00 \\
68(40.72) / 99 \\
(59.28)\end{array}$ & $\begin{array}{l}8.00 \\
68(14.38) / 405 \\
(85.62)\end{array}$ & $\begin{array}{l}U=24447.50^{* * *} \\
\chi^{2}(1)=51.18^{* * *}\end{array}$ \\
\hline
\end{tabular}

Depression

$\begin{array}{llll}\text { Total score } M d n & 9.00 & 5.00 & U=26512.00^{* * *} \\ \text { Above/Below cut-off } N(\%) & 78(46.71) / 89 & 121(25.58) / 352 & \chi^{2}(1)=25.71^{* * *} \\ & (53.29) & (74.42) & \end{array}$

Anxiety

Total score $M d n$
Above/Below cut-off $N(\%)$

7.00

4.00

$U=26589.50^{* * *}$

$59(35.33) / 108$

$88(18.60) / 385$

$\chi^{2}(1)=19.51^{* * *}$

(64.67)

(81.40)

Alcohol use

$$
\begin{aligned}
& \text { Total score } M d n \\
& \text { Above/Below cut-off } N(\%)
\end{aligned}
$$

8.00

7.00

$U=37470.50$

$69(41.32) / 98(58.68)$

$160(33.83) / 313$

$\chi^{2}(1)=3.01$

(66.17)

Social support 


$\begin{array}{llll}\text { Total score } M d n & 4.67 & 5.75 & U=26177.50^{* * *} \\ \text { Family } M d n & 4.25 & 5.75 & U=24939.50^{* * *} \\ \text { Friends } M d n & 4.75 & 5.50 & U=30378.50^{* * *} \\ \text { Significant other } M d n & 6.00 & 6.25 & U=35082.50^{*}\end{array}$

Note. All continuous variables were non-normally distributed. Significant differences between maltreated and non-maltreated groups based on Mann-Whitney $\mathrm{U}$ tests and chi-square difference tests are denoted by ${ }^{* * *} p$ $<.001 ; * * p<.01 ; * p<.05$. 
Table 2

Odds ratios and confidence intervals for direct and indirect effects.

\begin{tabular}{|c|c|c|c|c|c|c|}
\hline \multirow[b]{2}{*}{ Variable (reference } & \multicolumn{3}{|l|}{ Direct effects } & \multicolumn{3}{|c|}{ Indirect effects } \\
\hline & Model 1 & Model 2 & Model 3 & Family & Friends & Significant \\
\hline category) & OR (95\% CI) & OR (95\% CI) & OR (95\% CI) & B (SE) & B (SE) & B (SE) \\
\hline \multicolumn{7}{|l|}{ PTSD } \\
\hline Child abuse (no & $4.09(2.74-6.11)^{* * *}$ & $4.03(2.68-6.06)^{* * *}$ & $2.93(1.90-4.52)^{* * *}$ & $0.37(0.11)^{* * *}$ & $0.07(0.06)$ & $-0.01(0.02)$ \\
\hline \multicolumn{7}{|l|}{ abuse) } \\
\hline Age & - & $1.00(0.97-1.03)$ & $1.00(0.97-1.02)$ & $0.00(0.00)$ & $0.00(0.00)$ & $-0.00(0.00)$ \\
\hline Male gender & - & $0.58(0.35-0.96)^{*}$ & $0.54(0.31-0.92)^{*}$ & $0.01(0.05)$ & $0.03(0.03)$ & $-0.01(0.01)$ \\
\hline \multicolumn{7}{|l|}{ (female) } \\
\hline In relationship (not & - & $0.66(0.44-1.01)$ & $0.63(0.38-1.02)$ & $-0.10(0.06)$ & $0.01(0.02)$ & $0.07(0.12)$ \\
\hline \multicolumn{7}{|l|}{ in relationship) } \\
\hline SS Family & - & - & $0.72(0.61-0.84)^{* * *}$ & - & - & - \\
\hline SS Friends & - & - & $0.90(0.76-1.08)$ & - & - & - \\
\hline
\end{tabular}




\section{Depression}

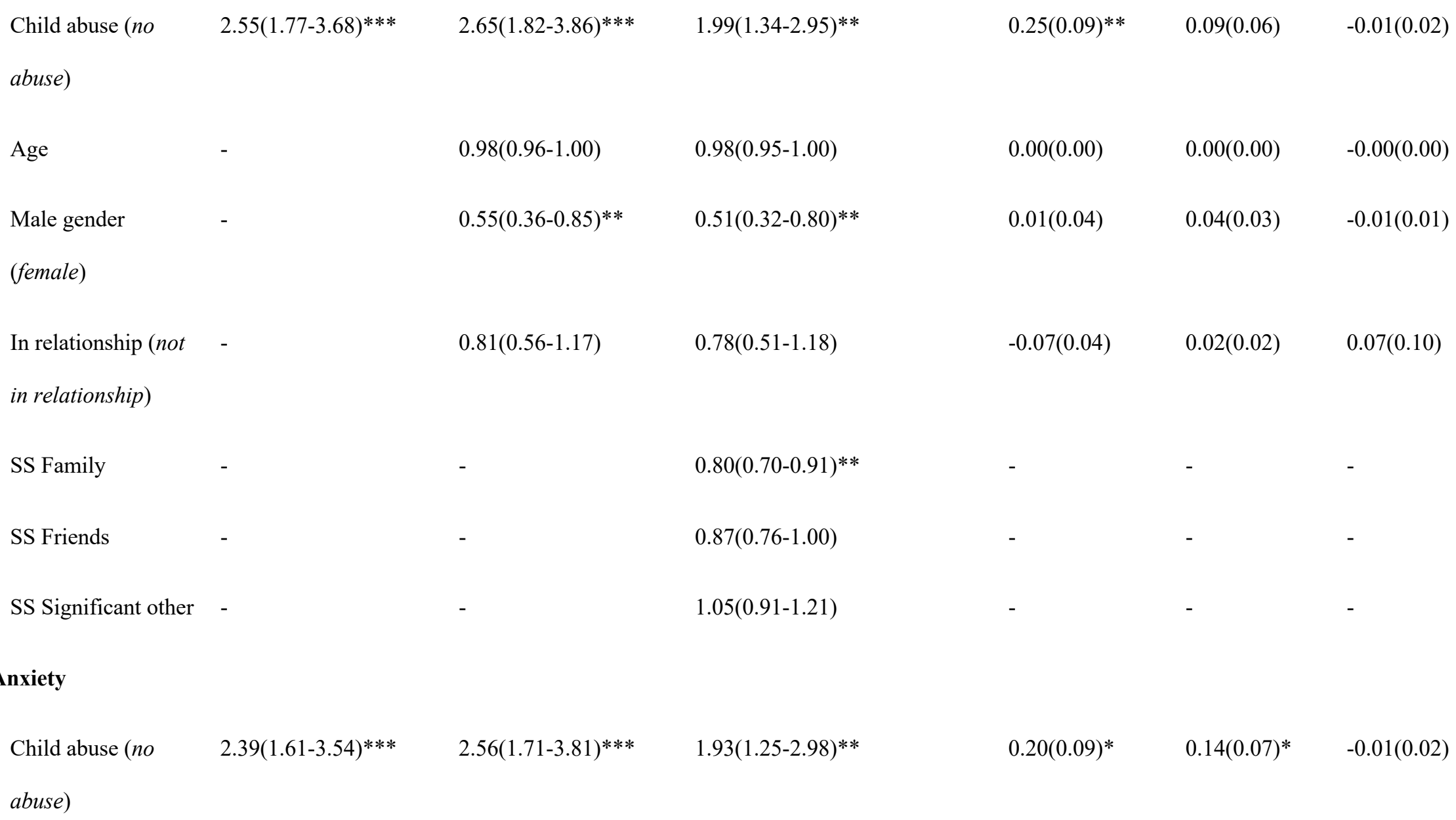




\begin{tabular}{|c|c|c|c|c|c|c|}
\hline Age & - & $0.97\left(0.94-1.00^{\wedge}\right)^{*}$ & $0.97\left(0.94-1.00^{\wedge \wedge}\right)^{*}$ & $0.00(0.00)$ & $0.00(0.00)$ & $0.00(0.00)$ \\
\hline $\begin{array}{l}\text { Male gender } \\
(\text { female })\end{array}$ & - & $0.60(0.37-0.98)^{*}$ & $0.54(0.32-0.91)^{*}$ & $0.01(0.03)$ & $0.06(0.04)$ & $-0.00(0.01)$ \\
\hline $\begin{array}{l}\text { In relationship (not } \\
\text { in relationship) }\end{array}$ & - & $0.98(0.65-1.46)$ & $0.94(0.58-1.52)$ & $-0.05(0.04)$ & $0.03(0.03)$ & $0.03(0.12)$ \\
\hline SS Family & - & - & $0.84(0.72-0.98)^{*}$ & - & - & - \\
\hline SS Friends & - & - & $0.81(0.69-0.95)^{*}$ & - & - & - \\
\hline $\begin{array}{l}\text { SS Significant other } \\
\text { Icohol use }\end{array}$ & - & - & $1.02(0.88-1.19)$ & - & - & - \\
\hline $\begin{array}{l}\text { Child abuse (no } \\
\text { abuse) }\end{array}$ & $1.38(0.96-1.98)$ & $1.44(0.99-2.10)$ & $1.37(0.92-2.04)$ & $0.11(0.08)$ & $-0.07(0.05)$ & $0.01(0.01)$ \\
\hline Age & - & $0.98(0.96-1.01)$ & $0.98(0.96-1.01)$ & $0.00(0.00)$ & $0.00(0.00)$ & $0.00(0.00)$ \\
\hline $\begin{array}{l}\text { Male gender } \\
(\text { female })\end{array}$ & - & $1.58(1.08-2.29)^{*}$ & $1.62(1.11-2.36)^{*}$ & $0.00(0.02)$ & $-0.03(0.03)$ & $0.00(0.01)$ \\
\hline
\end{tabular}


In relationship (not

$0.61(0.43-0.87)^{* *}$

in relationship)

SS Family

SS Friends

SS Significant other
$0.67(0.45-0.99)^{*}$

$0.91(0.80-1.03)$

$1.10(0.97-1.26)$

$0.97(0.85-1.11)$
$-0.03(0.03)$

$-0.01(0.02)$

$-0.04(0.10)$

Note. ${ }^{* * *} p<.001 ;{ }^{* *} p<.01 ;{ }^{*} p<.05$

$\mathrm{CI}=$ confidence interval; $\mathrm{OR}=$ odds ratio $; \mathrm{SS}=$ Social support

$\wedge^{\wedge}$ Rounded up from $0.998 ; \wedge \wedge$ Rounded up from 0.997 
Figure 1

Final mediation model

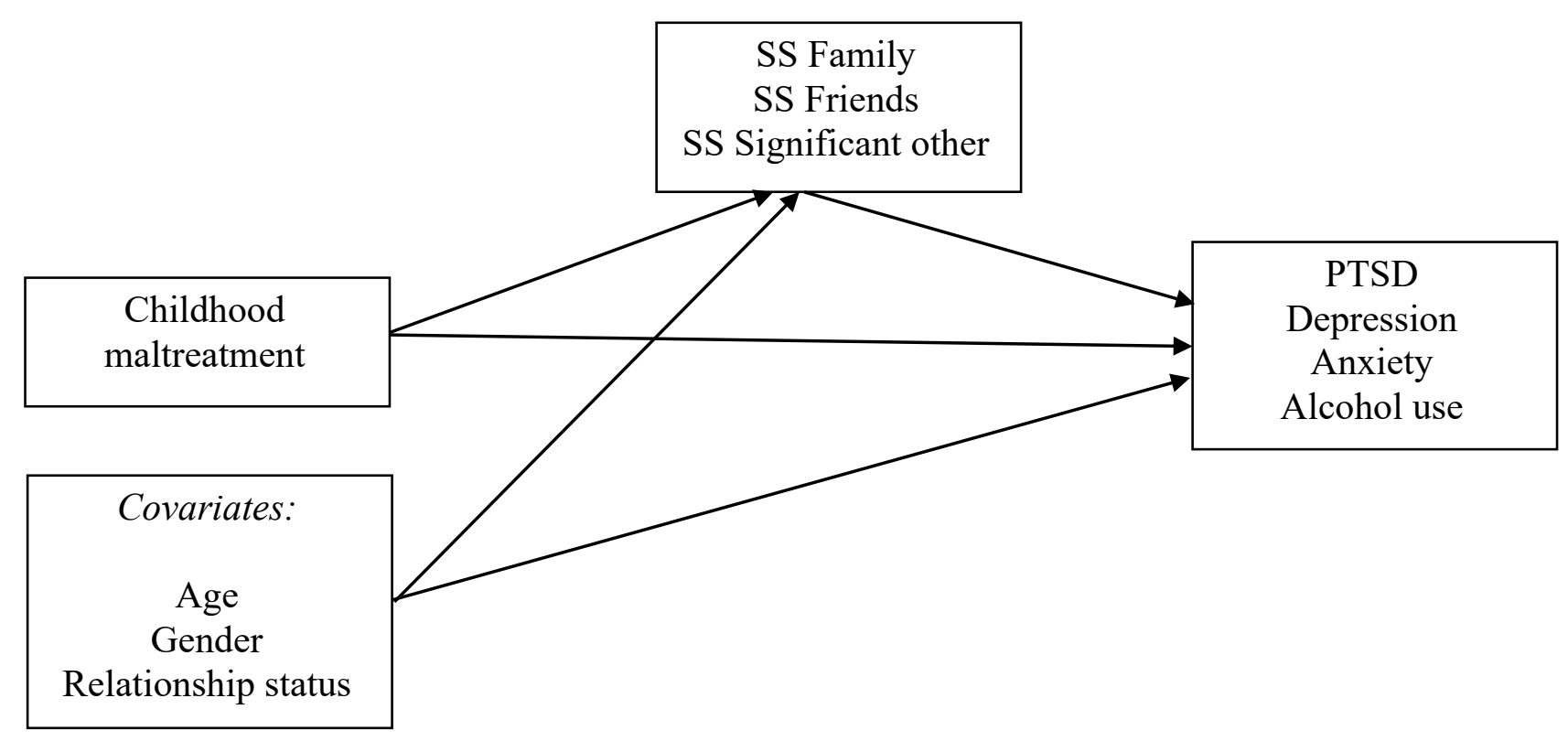

Note. SS $=$ Social support 